\title{
Simple room-temperature preparation of high-yield large-area graphene oxide
}

This article was published in the following Dove Press journal:

International Journal of Nanomedicine

16 December 201I

Number of times this article has been viewed

\author{
NM Huang' \\ HN Lim² \\ $\mathrm{CH} \mathrm{Chia}{ }^{3}$ \\ MA Yarmo ${ }^{4}$ \\ MR Muhamad ${ }^{5}$ \\ 'Low Dimensional Materials Research \\ Centre, Physics Department, \\ University of Malaya, Kuala Lumpur, \\ Malaysia; ${ }^{2}$ Centre for lonics University \\ of Malaya, Physics Department, \\ University of Malaya, Kuala Lumpur, \\ Malaysia; ${ }^{3}$ School of Applied Physics, \\ Faculty of Science and Technology, \\ Universiti Kebangsaan, Malaysia; \\ ${ }^{4}$ School of Chemical Sciences \\ and Food Technology, Faculty of \\ Science and Technology, Universiti \\ Kebangsaan, Malaysia; ${ }^{5}$ Chancellery \\ Office, Multimedia University, Jalan \\ Multimedia, Selangor Darul Ehsan, \\ Malaysia
}

Correspondence: NM Huang

Low Dimensional Materials Research

Centre, Physics Department, University

of Malaya, 50603 Kuala Lumpur, Malaysia

Tel +60122091008

Fax +6037967 4I46

Email huangnayming@gmail.com
Abstract: Graphene has attracted much attention from researchers due to its interesting mechanical, electrochemical, and electronic properties. It has many potential applications such as polymer filler, sensor, energy conversion, and energy storage devices. Graphene-based nanocomposites are under an intense spotlight amongst researchers. A large amount of graphene is required for preparation of such samples. Lately, graphene-based materials have been the target for fundamental life science investigations. Despite graphene being a much sought-after raw material, the drawbacks in the preparation of graphene are that it is a challenge amongst researchers to produce this material in a scalable quantity and that there is a concern about its safety. Thus, a simple and efficient method for the preparation of graphene oxide (GO) is greatly desired to address these problems. In this work, one-pot chemical oxidation of graphite was carried out at room temperature for the preparation of large-area GO with $\sim 100 \%$ conversion. This high-conversion preparation of large-area GO was achieved using a simplified Hummer's method from large graphite flakes (an average flake size of $500 \mu \mathrm{m}$ ). It was found that a high degree of oxidation of graphite could be realized by stirring graphite in a mixture of acids and potassium permanganate, resulting in GO with large lateral dimension and area, which could reach up to $120 \mu \mathrm{m}$ and $\sim 8000 \mu \mathrm{m}^{2}$, respectively. The simplified Hummer's method provides a facile approach for the preparation of large-area GO.

Keywords: graphene oxide, simplified Hummer's method, chemical oxidation

\section{Introduction}

Graphene is a versatile two-dimensional material with applications not confined only to electronic devices. Biologists show keen interest in graphene, and various studies have been carried out to investigate its biocompatibility with cells (eg, A549 mammalian cell line on graphene and graphene oxide [GO] paper, NIH-3T3 mouse fibroblast cells on graphene-carbon nanotube, L929 mouse fibroblast cells on graphene- and GO-polyaniline and graphene-reinforced chitosan, ARPE-19 retinal pigment epithelium cells on GO-glucose oxidase, A549 human lung carcinoma epithelial cells on GO, nano-reduced GO functionalized noncovalently by amphiphilic PEGylated polymer chains, and nano-GO covalently PEGylated on U87MG human glioblastoma and MCF-7 human breast cancer cell lines). ${ }^{1}$ Our recent work has indicated that graphene, in the form of a three-dimensional structure, may be a promising scaffold for cell growth. ${ }^{1}$ In addition to biocompatibility investigations, the use of graphene has been extended to bacterial eradication, including Escherichia coli, Staphylococus aureus, Pseudomonas aeruginosa, and Bacillus cereus. ${ }^{2-6}$ 
The most popular method employed for the synthesis of graphene is chemical oxidation of graphite. ${ }^{7}$ This method involves oxidation of graphite to GO using highly oxidizing reagents and subsequently reducing GO to graphene using various reductants. The advantage of this method is the formation of a large quantity of graphene in powder form (scalability), which is dispersible in both polar and nonpolar solvents by functionalizing the surface of graphene. ${ }^{8}$ Chemical oxidation of graphite is an established method using concentrated acids (sulfuric acid, nitric acid, and phosphoric acid) and highly oxidizing agents (potassium permanganate and potassium perchlorate). However, the oxidation method usually requires several steps and temperature controls for the preparation of GO. A simpler method for oxidation is required for efficient synthesis of GO.

Most of the GO and reduced GO reported previously possessed small area and lateral dimension, which is approximately $100 \mu \mathrm{m}^{2}$ and a few hundred nanometers to a few microns, respectively. ${ }^{9-13}$ It is difficult to produce large-area GO due to the unavoidable tearing of GO sheets during the extreme oxidation condition and exfoliation process using ultrasonication. Large-area GO has been reported since 2009 by Tung et al ${ }^{14}$ with area $<2000 \mu \mathrm{m}^{2}$ and lateral dimension of $20 \mu \mathrm{m} \times 40 \mu \mathrm{m}$. Later, two groups reported the synthesis of ultralarge GO sheets by modifying the oxidation/exfoliation of Hummer's method. ${ }^{15,16}$ Recently, Zhao et $\mathrm{al}^{17}$ reported an efficient method to produce largearea GO with an area of $7000 \mu \mathrm{m}^{2}$ and a lateral dimension of up to $100 \mu \mathrm{m}$. However, the yield of the GO obtained was about $10 \%$, which is very low. Prior to that, Luo et al ${ }^{18}$ reported the formation of GO with high yield, reaching almost $100 \%$, but the size of the GO produced was merely about $2000 \mathrm{um}^{2}$. Furthermore, the method involved a long and tedious oxidation process.

Marcano et $\mathrm{al}^{19}$ recently reported the synthesis of GO using an improved Hummer's method. This method introduced a relatively simple oxidation process, with temperature controlled at $50^{\circ} \mathrm{C}$, which was rather low compared with the previously reported temperature of $95^{\circ} \mathrm{C}$. However, the washing process was time-consuming and tedious. Moreover, the emphasis of the method was not on producing large-area GO but more on controlling the level of oxidation and degree of ordering in GO. The conversion rate of graphite to GO was not $100 \%$.

In order to achieve commercial value, the synthesis process of GO needs to be simplistic and cost effective. Current methods of producing GO using chemical oxidation like Hummer's method, ${ }^{20}$ Staudeumaier's method, ${ }^{21}$ and
Brodie's method ${ }^{22}$ involved tedious and long experimental time. Here, the experimental time does not refer to the time required to oxidize the graphite flakes but rather the time spent by a researcher working on the experiment during the oxidation process. The long hours of mixing the reactants and cooling or heating the reactants have been reduced from 3-5 hours to less than 5 minutes in this work. Graphite oxidation was achieved simply by adding graphite and potassium permanganate $\left(\mathrm{KMnO}_{4}\right)$ into concentrated acids (containing sulfuric acid, with or without phosphoric acid) under constant stirring. The whole process was carried out without any temperature control, neither increasing nor decreasing the temperature. The mixture was stirred at room temperature for up to 3 days to achieve a high degree of oxidation.

\section{Experimental details Materials}

Graphite flakes (code no 3061) were purchased from Asbury Graphite Mills, Inc (Asbury, NJ). Sulfuric acid $\left(\mathrm{H}_{2} \mathrm{SO}_{4}, 98 \%\right.$ ), phosphoric acid $\left(\mathrm{H}_{3} \mathrm{PO}_{4}, 85 \%\right)$, potassium permanganate $\left(\mathrm{KMnO}_{4}, 99.9 \%\right)$, and hydrogen peroxide $\left(\mathrm{H}_{2} \mathrm{O}_{2}, 30 \%\right)$, were purchased from Merck (Darmstadt, Germany). Hydrogen chloride $(\mathrm{HCl}, 37 \%)$ was purchased from Sigma-Aldrich (St Louis, MO).

\section{Graphene oxide synthesis}

Oxidation of graphite was carried out by mixing $\mathrm{H}_{2} \mathrm{SO}_{4}: \mathrm{H}_{3} \mathrm{PO}_{4}$ (320:80 mL), graphite flakes, and $\mathrm{KMnO}_{4}(18 \mathrm{~g})$ using a magnetic stirrer. After adding all the materials slowly, the one-pot mixture was left for stirring for 3 days to allow the oxidation of graphite. The color of the mixture changed from dark purplish green to dark brown. Later, $\mathrm{H}_{2} \mathrm{O}_{2}$ solution was added to stop the oxidation process, and the color of the mixture changed to bright yellow, indicating a high oxidation level of graphite. The graphite oxide formed was washed three times with $1 \mathrm{M}$ of $\mathrm{HCl}$ aqueous solution and repeatedly with deionized water until a $\mathrm{pH}$ of 4-5 was achieved. The washing process was carried out using simple decantation of supernatant via a centrifugation technique with a centrifugation force of $10,000 \mathrm{~g}$. During the washing process with deionized water, the graphite oxide experienced exfoliation, which resulted in the thickening of the graphene solution, forming a GO gel.

\section{Characterization}

The area, size, and morphology of the prepared GO were characterized using an FEI Nova NanoSEM 400 field emission scanning electron microscope (FESEM; FEI, 
Hillsboro, OR). The lateral dimension and area of the graphene sheets were measured using I-Solution image analysis software. Atomic force microscopy (AFM) was performed on Agilent 5500 (Agilent Technologies, Inc, Santa Clara, CA), and a tapping mode was employed to determine the thickness of GO. GO was spin-coated at 1500 rpm for 1 minute on a freshly cleaved mica substrate. The $\mathrm{X}$-ray diffraction (XRD) pattern was recorded using a Phillip X-ray diffractometer (Philips, Amsterdam, the Netherlands), employing a scanning rate of $0.033^{\circ} \mathrm{s}^{-1}$ in a $2 \theta$ range from $5^{\circ}$ to $80^{\circ}$ with $\mathrm{Cu} \mathrm{K} \alpha$ radiation $(\lambda=1.5418 \AA$ ) $)$. Samples for XRD analysis were prepared by spin-coating GO gel on quartz glasses. Ultraviolet-visible spectra were recorded on a Thermo Scientific Evolution 300 spectrophotometer. Chemical bonding was analyzed using a Kratos AXIS Ultra DLD X-ray photoelectron spectrometer.

\section{Results and discussion}

We carried out the preparation of large-area GO using our simplified Hummer's method. This simplified method does not involve controlling temperature during the chemical oxidation of graphite. Unlike the commonly practiced processes where an ice bath is required during the initial addition of $\mathrm{KMnO}_{4}$ and heating during the oxidation stage, our simplified approach is hassle-free. The slight exothermic process, which increases the temperature to $40^{\circ} \mathrm{C}-50^{\circ} \mathrm{C}$ after the addition of $\mathrm{H}_{2} \mathrm{O}_{2}$ solution to terminate the oxidation process, will cool down naturally in a short time. This experiment is relatively safe, and the danger of explosion is reduced significantly, in contrast to the normal route of chemical oxidation of graphite. Furthermore, the mixing and washing steps are simple and straightforward, yielding an almost 100\% conversion of large-area GO.

To study the effect of oxidation level we used $\mathrm{KMnO}_{4}$ :acid $\left(\mathrm{H}_{2} \mathrm{SO}_{4}: \mathrm{H}_{3} \mathrm{PO}_{4}\right)$ at the weight ratios of $1: 80,1: 40$, and $1: 20$ (hereon denoted as KS-80, KS-40, and KS-20, respectively, where the weight ratio of $\mathrm{H}_{2} \mathrm{SO}_{4}: \mathrm{H}_{3} \mathrm{PO}_{4}$ was fixed at 9:1) and the weight ratio of graphite:sulfuric acid was maintained at 1:100 for all the samples. Oxidation time was fixed at 6 hours, 1 day, 2 days, and 3 days, respectively, to evaluate the oxidation level effects on GO. The samples were gently sonicated for 5 minutes prior to FESEM viewing.

Table 1 shows the average lateral dimension of the GO produced with different ratios of $\mathrm{KMnO}_{4}$ :acids and oxidation time (6 hours to 3 days). After 6 hours of oxidation, GO with an average lateral dimension of $18.7 \mu \mathrm{m}$ was formed in KS-20, which was larger than that of KS-40 and KS-80. The conversion was very low, as observed from the large amount
Table I Average lateral dimension of graphene oxide for different reaction parameters.

\begin{tabular}{lllll}
\hline Samples & \multicolumn{4}{l}{$\begin{array}{l}\text { Average lateral dimension after oxidation time } \\
(\boldsymbol{\mu m})\end{array}$} \\
\cline { 2 - 5 } & $\mathbf{6}$ hours & I day & 2 days & 3 days \\
\hline $\mathrm{KS}-20$ & $18.7 \mu \mathrm{m}$ & $40.3 \mu \mathrm{m}$ & $49.3 \mu \mathrm{m}$ & $58.3 \mu \mathrm{m}$ \\
$\mathrm{KS}-40$ & $10.2 \mu \mathrm{m}$ & $17.5 \mu \mathrm{m}$ & $22.3 \mu \mathrm{m}$ & $37.5 \mu \mathrm{m}$ \\
$\mathrm{KS}-80$ & $5.1 \mu \mathrm{m}$ & $7.5 \mu \mathrm{m}$ & $9.3 \mu \mathrm{m}$ & $13.4 \mu \mathrm{m}$ \\
\hline
\end{tabular}

Note: The resultant graphene oxide was sonicated gently for 5 minutes prior to viewing under field emission scanning electron microscopy.

of precipitate after centrifugation for 5 minutes at $4000 \mathrm{rpm}$, indicating un exfoliated or unoxidized graphite. The amount of precipitate observed in KS-80 and KS-40 was even greater than KS-20. After 1 day of oxidation, a similar result was observed as compared with an oxidation time of 6 hours. However, the average size of GO had increased for the three ratios. When the oxidation time increased to 2 days, GO in KS-20, KS-40, and KS-80 increased in size as compared with after 1 day of oxidation. The lack of precipitate after centrifugation suggests that KS-20 had the highest yield of $\mathrm{GO}$, even though the oxidation process was not yet optimized. At day 3, KS-20 achieved a 100\% conversion of graphite to $\mathrm{GO}$, as precipitate was not found after centrifugation. The size of the GO produced is large, with an average lateral dimension of $58.3 \mu \mathrm{m}$.

Figure 1A, B, and C show the FESEM micrographs of graphene prepared using three different ratios of $\mathrm{KMnO}_{4}$ :acids (KS-80, KS-40, and KS-20) after 3 days of oxidation. The GO

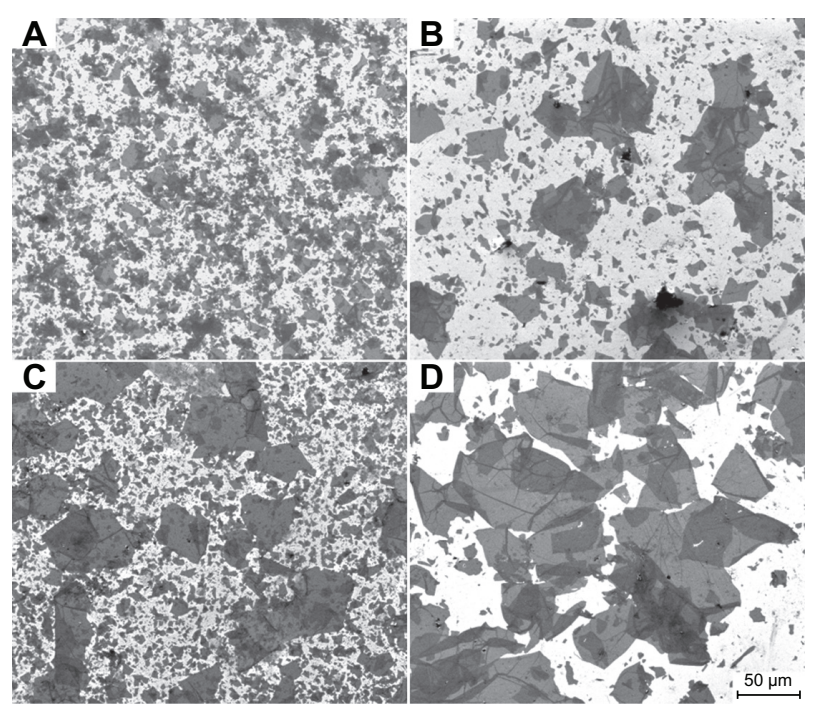

Figure I Field emission scanning electron microscopy micrographs of graphene oxide prepared in (A) KS-80, (B) KS-40, and (C) KS-20 after 3 days of oxidation and (D) nonsonicated KS-20. All the micrographs were taken at the same magnification. 

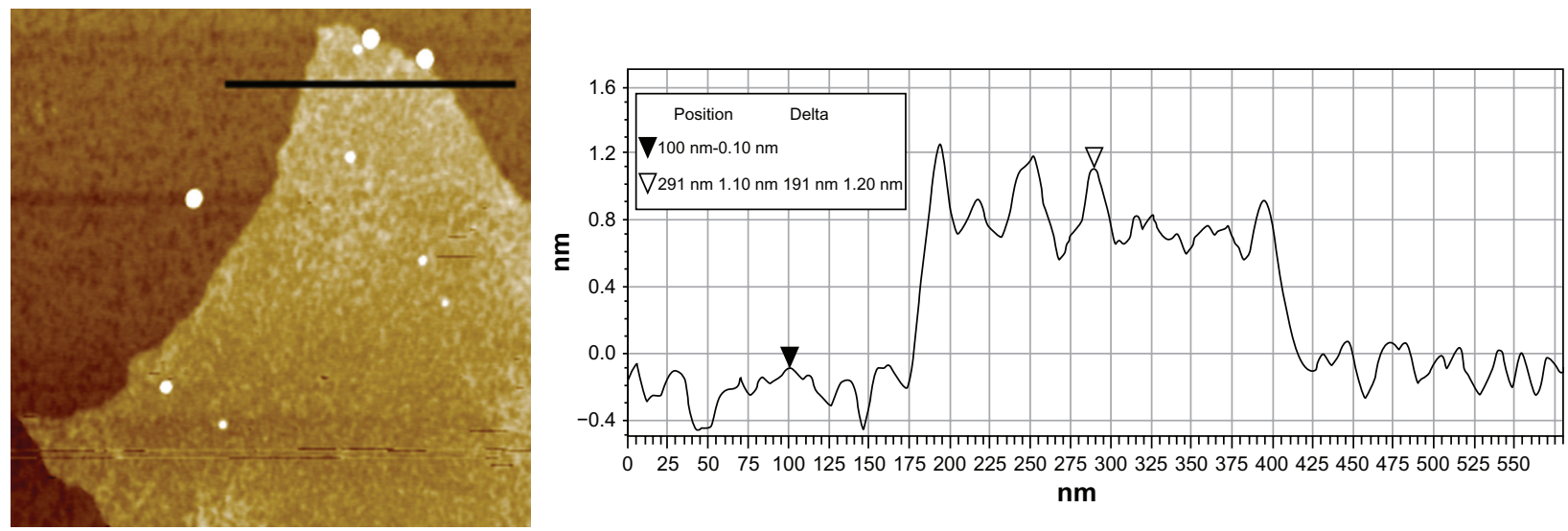

Figure 2 Atomic force microscopy measurement of graphene oxide (scan area: I $\mu \mathrm{m} \times 1 \mu \mathrm{m}$ ). Tapping mode atomic force microscopy image of single-layer graphene oxide (KS-20) with corresponding height cross-sectional profile with an average thickness of I.2 nm. The sample was spin-coated on a freshly cleaved mica substrate.

samples were gently sonicated for 5 minutes using $80 \mathrm{~W}$ power of sonication before being spin-coated on $\mathrm{SiO}_{2} / \mathrm{Si}$ wafer and viewed under FESEM. From the micrographs, it was found that the average lateral dimension of GO increased as the ratio of $\mathrm{KMnO}_{4}$ :acid increased. $\mathrm{KS}-20$ with the highest concentration of $\mathrm{KMnO}_{4}$ produced the largest $\mathrm{GO}$ (Figure 1C). However, due to the sonication effect, the average lateral dimension of graphene becomes $58.3 \mu \mathrm{m}$. On the contrary, nansonicated GO in KS-20 presents uniform sheets of GO with an average lateral dimension of $95.1 \mu \mathrm{m}$ (up to $120 \mathrm{um}$ ) and an area of $\sim 8000 \mu \mathrm{m}^{2}$ (Figure 1D).

These observations are different from the reported investigations on the effects of oxidation on the size of GO. It was previously reported that the size of GO reduced with a higher degree of oxidation. ${ }^{17,23}$ However, by using our proposed simplified Hummer's method, GO with a large lateral dimension is produced with a higher degree of oxidation. This can be explained by the fact that the initial graphite used for previous works is smaller in size as compared with that of ours, and the graphite may have overoxidized under elevated temperature $\left(95^{\circ} \mathrm{C}\right)$. As for our sample, the optimum oxidation time was 3 days (for $\mathrm{KS}-20$ ) with the $\mathrm{GO}$ produced possessing the largest dimension. However, after 4 days of oxidation, the GO produced showed small lateral dimension in the range of $<20 \mu \mathrm{m}$ (FESEM micrograph not shown).

Based on the FESEM images, a plausible mechanism for the formation of large-area GO is a complete oxidation of graphite but not overly oxidized, as it could lead to tearing of the GO. The complete oxidation condition resulted in graphite oxide to be exfoliated easily in large pieces. Another contributing factor that leads to the formation of large GO is that the reactions were carried out at room temperature. It has been reported that high temperature during the oxidation process reduces the size of the GO produced. ${ }^{17}$
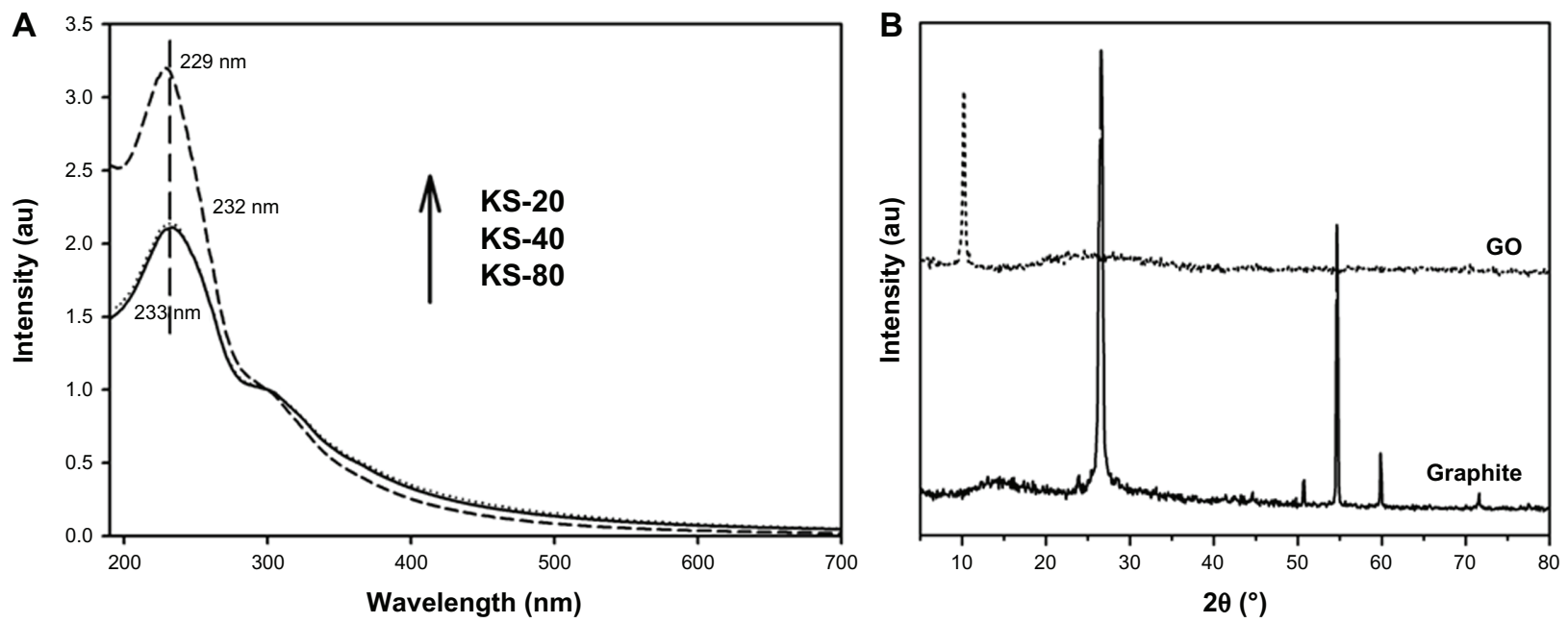

Figure 3 (A) Ultraviolet-visible absorbance spectra of graphene oxide after 3 days of oxidation time, and (B) X-ray diffraction patterns of graphite flakes and graphene oxide. 
The large-area graphene for sample KS-20 after 3 days of oxidation was measured using atomic force microscopy to determine the thickness of the GO produced. A typical tapping mode AFM image and the corresponding height cross-section profile of the GO sheets deposited on a mica substrate are shown in Figure 2. Based on the AFM height profile analysis, the thickness of the KS-20 GO sample is around $1.2 \mathrm{~nm}$. The result is consistent with the thickness of the characteristic single-layer GO reported. ${ }^{17,24}$

Ultraviolet-visible spectroscopy measurement was carried out to monitor the degree of oxidation for the graphene samples. The spectra for KS-80, KS-40, and KS-20 were recorded after 3 days of oxidation, as shown in Figure 3A, with absorption peaks at $233 \mathrm{~nm}, 232 \mathrm{~nm}$, and $229 \mathrm{~nm}$, respectively. These peaks are due to the $\pi \rightarrow \pi^{*}$ transition for the $\mathrm{C}=\mathrm{C}$ bonding, which is similar to the reported value in the literature. ${ }^{25}$ The peak position for KS-20 sample exhibits the lowest wavelength, indicating that the sample has a lower amount of remaining conjugation (thus requires higher energy for the electronic transition) as compared with the other two samples (KS-40 and KS-80), which is due to the higher degree of oxidation with more functional groups on the GO basal plane. Also, there is a similar shoulder around $300 \mathrm{~nm}$ observed for all the three samples, which is attributed to $\mathrm{n} \rightarrow \pi^{*}$ transition of the carbonyl groups. Another observation on the ratio of the intensity of $\mathrm{C}=\mathrm{C}$ bonding peak $(\sim 230 \mathrm{~nm})$ to the intensity of $300 \mathrm{~nm}$ peak finds that the higher the degree of oxidation, the greater the ratio. This is because a more oxidized graphene basal plane yields a greater amount of isolated aromatic rings that increase the intensity of $\mathrm{C}=\mathrm{C}$ bonding peak. In contrast, a less oxidized graphene basal plane gives rise to a lesser amount of isolated aromatic rings and remained in the extended conjugated aromatic rings form, and therefore the intensity of $\mathrm{C}=\mathrm{C}$ bonding peak is relatively low. ${ }^{19}$ In this scenario, the peak intensity ratio for KS-20 is 3.2, and 2.1 for both KS- 80 and KS-40, respectively. To the best of our knowledge, the reported ultraviolet-visible spectra for GO in the literature have ratios that fall within the range of $<2$, in which the lateral dimension of the GO produced is significantly smaller.

XRD patterns in Figure 3B show a distinct diffraction peak at $10.24^{\circ}$ for $\mathrm{GO}$ and $26.56^{\circ}$ for graphite flakes. The interlayer spacing values for graphite flakes and GO are $0.34 \mathrm{~nm}$ and $0.87 \mathrm{~nm}$, respectively. The distance between consecutive carbon layers was increased for $\mathrm{GO}$ due to the introduction of oxide functional groups to the carbon basal plane via chemical oxidation reaction. This increased interlayer spacing for $\mathrm{GO}$ is in line with the results measured from AFM.
In Figure 4, the C1 s band of the GO samples (KS-20, KS-40, and KS-80 after 3 days of oxidation) can be fitted to four deconvulated components, located at $284.3 \mathrm{eV}$, $286.6 \mathrm{eV}, 287 \mathrm{eV}$, and $288.6 \mathrm{eV}$. These components can be assigned to the nonoxygenated ring carbon, $\mathrm{C}$ in $\mathrm{C}-\mathrm{O}, \mathrm{C}$ in $\mathrm{C}=\mathrm{O}$, and $\mathrm{C}$ in $\mathrm{C}(\mathrm{O}) \mathrm{O}$, respectively, which are separated by $\sim 2.0 \mathrm{eV}, 1.0 \mathrm{eV}, 1.0 \mathrm{eV}$, and $1.0 \mathrm{eV}^{26}$ All the oxygenated features increased in intensity as the concentration of $\mathrm{KMnO}_{4}$ increased from KS-80 to KS-20. The components that experienced the highest degree of oxidation is the $\mathrm{C}$ in $\mathrm{C}=\mathrm{O}$ for $\mathrm{KS}-20$, as can be seen from the high-intensity peak at around $287 \mathrm{eV}$. The components are in agreement with the results in the literature for similar $\mathrm{C} 1 \mathrm{~s}$ band shapes. ${ }^{13,27,28}$ These X-ray

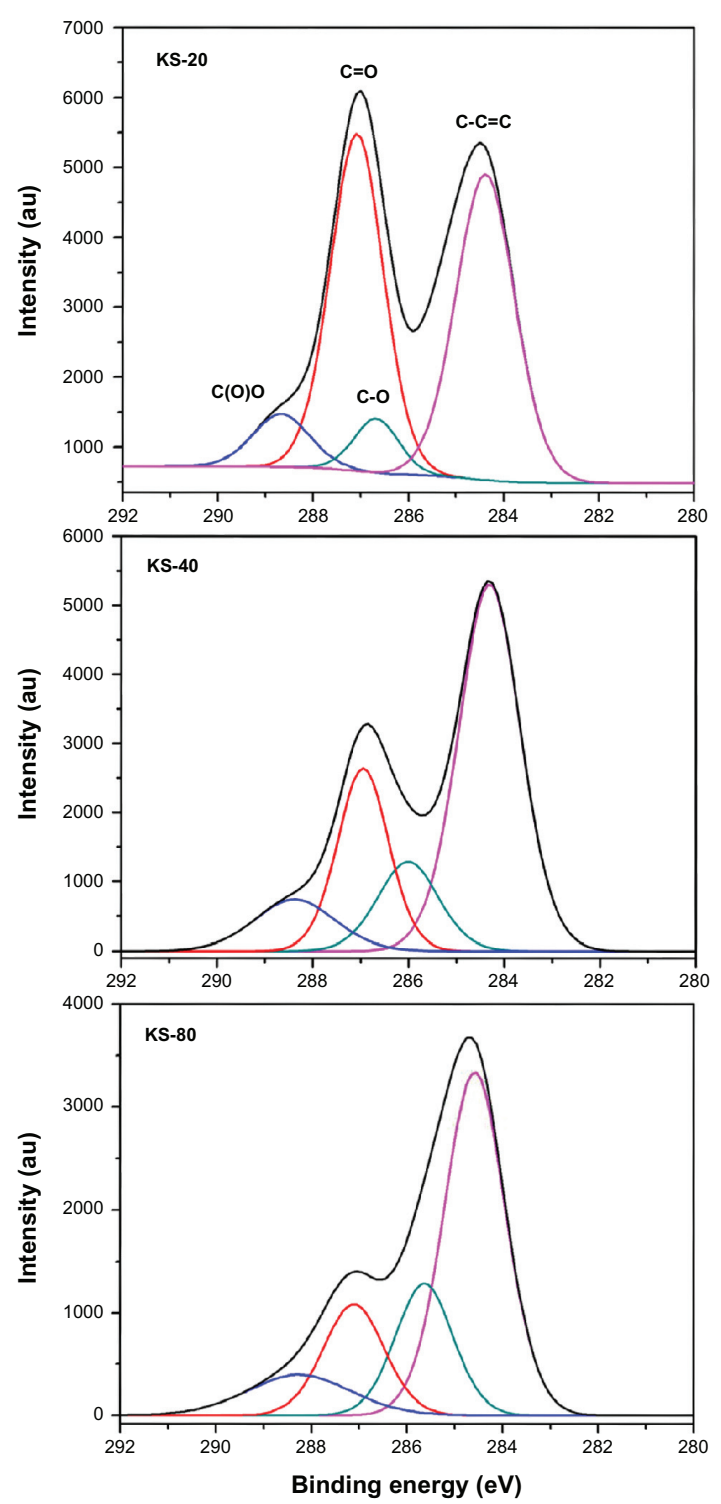

Figure 4 X-ray photoelectron spectrometry analysis of graphene oxide with different degrees of oxidation illustrating the deconvoluted $X$-ray photoelectron spectra in the $\mathrm{CI}$ s peak region for the KS-20, KS-40, and KS- 80 samples. 
photoelectron spectrometry results are in accordance with the ultraviolet-visible analysis, revealing that the concentration of $\mathrm{KMnO}_{4}$ directly influenced the degree of oxidation.

\section{Conclusion}

We report a highly facile method for the preparation of scalable large-area GO. The method was carried out at room temperature with the highest conversion possible $(100 \%$ conversion of graphite flakes to GO) to produce largearea GO without ultrasonication. Here, we have identified key factors contributing to the large area of GO formed, which are complete oxidation of graphite through a high degree of oxidation and the need to carry out the reaction at room temperature. Our method of synthesizing GO will infinitely increase the rate of $\mathrm{GO}$ production for numerous investigations, which might appeal to biologists, chemists, physicists, and materials scientists.

\section{Acknowledgment}

This work was supported by the High Impact Research Grant of the University of Malaya (UM.C/625/1/HIR/030) and the High Impact Research Grant under the Ministry of Higher Education of Malaysia (UM.C/625/1/HIR/MOHE/05).

\section{Disclosure}

The authors report no conflicts of interest in this work.

\section{References}

1. Lim HN, Huang NM, Lim SS, Harrison I, Chia CH. Fabrication and characterization of graphene hydrogel via hydrothermal approach as a scaffold for preliminary study of cell growth. Int J Nanomed. 2011;6: $1817-1823$

2. Hu W, Peng C, Luo W, et al. Graphene-based antibacterial paper. ACS Nano. 2010;4:4317-4323.

3. Akhavan O, Ghaderi E. Toxicity of graphene and graphene oxide nanowalls against bacteria. ACS Nano. 2010;4:5731-5736.

4. Das MR, Sarma RK, Saikia R, Kale VS, Shelke MV, Sengupta P. Synthesis of silver nanoparticles in an aqueous suspension of graphene oxide sheets and its antimicrobial activity. Colloid Surf B. 2011;83: $16-22$.

5. Park S, Mohanty N, Suk JW, et al. Biocompatible, robust free-standing paper composed of a TWEEN/graphene composite. Adv Mater. 2010;22: $1736-1740$.

6. Akhavan O, Ghaderi E. Photocatalytic reduction of graphene oxide nanosheets on $\mathrm{TiO}_{2}$ thin film for photoinactivation of bacteria in solar light irradiation. J Phys Chem C. 2009;113:20214-20220.

International Journal of Nanomedicine

\section{Publish your work in this journal}

The International Journal of Nanomedicine is an international, peerreviewed journal focusing on the application of nanotechnology in diagnostics, therapeutics, and drug delivery systems throughout the biomedical field. This journal is indexed on PubMed Central, MedLine, CAS, SciSearch ${ }^{\circledR}$, Current Contents ${ }^{\circledR} /$ Clinical Medicine,
7. Dreyer DR, Park S, Bielawski CW, Ruoff RS. The chemistry of graphene oxide. Chem Soc Rev. 2010;39:228-2240.

8. Gao J, Liu F, Liu Y, Ma N, Wang Z, Zhang X. Environment-friendly method to produce graphene that employs vitamin $\mathrm{C}$ and amino acid. Chem Mater. 2010;22:2213-2218.

9. Ju H-M, Huh SH, Choi S-H, Lee H-L. Structures of thermally and chemically reduced graphene. Mater Lett. 2010;64:357-360.

10. Zhang T, Zhang D, Shen M. A low-cost method for preliminary separation of reduced graphene oxide nanosheets. Mater Lett. 2009;63: 2051-2054.

11. Chen L, Xu Z, Li J, et al. Reduction and disorder in graphene oxide induced by electron-beam irradiation. Mater Lett. 2011;65:1229-1230.

12. Yang S-T, Chen S, Chang Y, Cao A, Liu Y, Wang H. Removal of methylene blue from aqueous solution by graphene oxide. $J$ Colloid Interface Sci. 2011;359:24-29.

13. Stankovich S, Dikin DA, Piner RD, et al. Synthesis of graphene-based nanosheets via chemical reduction of exfoliated graphite oxide. Carbon. 2007;45:1558-1565.

14. Tung VC, Allen MJ, Yang Y, Kaner RB. High-throughput solution processing of large-scale graphene. Nat Nano. 2009;4:25-29.

15. Su C-Y, Xu Y, Zhang W, et al. Electrical and spectroscopic characterizations of ultra-large reduced graphene oxide monolayers. Chem Mater. 2009;21:5674-5680.

16. Zhou X, Liu Z. A scalable, solution-phase processing route to graphene oxide and graphene ultralarge sheets. Chem Commun. 2010;46: 2611-2613.

17. Zhao J, Pei S, Ren W, Gao L, Cheng H-M. Efficient preparation of large-area graphene oxide sheets for transparent conductive films. ACS Nano. 2010;4:5245-5252.

18. Luo Z, Lu Y, Somers LA, Johnson ATC. High yield preparation of macroscopic graphene oxide membranes. J Am Chem Soc. 2009;131: 898-899.

19. Marcano DC, Kosynkin DV, Berlin JM, et al. Improved synthesis of graphene oxide. ACS Nano. 2010;4:4806-4814.

20. Hummers WS, Offeman RE. Preparation of graphitic oxide. JAm Chem Soc. 1958;80:1339.

21. Staudenmaier L. [Method of preparation of graphite-acid]. Berichte der Deutschen Chemischen Gesellschaft. 1898;31:1481-1499. German.

22. Brodie BC. On the atomic weight of graphite. Philos Trans R Soc Lond. 1859;149:249-259.

23. Zhang L, Liang J, Huang Y, Ma Y, Wang Y, Chen Y. Size-controlled synthesis of graphene oxide sheets on a large scale using chemical exfoliation. Carbon. 2009;47:3365-3368.

24. Dikin DA, Stankovich S, Zimney EJ, et al. Preparation and characterization of graphene oxide paper. Nature. 2007;448:457-460.

25. Mei Q, Zhang K, Guan G, Liu B, Wang S, Zhang Z. Highly efficient photoluminescent graphene oxide with tunable surface properties. Chem Commun. 2010;46:7319-7321.

26. Zhang WC, Carravetta V, Li Z, Luo Y, Yang J. Oxidation states of graphene: insights from computational spectroscopy. J Chem Phys. 2009;131:244505-244511.

27. Fan ZJ, Kai W, Yan J, et al. Facile synthesis of graphene nanosheets via Fe reduction of exfoliated graphite oxide. ACS Journal. 2010;5: 191-198.

28. Geng Y, Wang SJ, Kim J-K. Preparation of graphite nanoplatelets and graphene sheets. J Colloid Interface Sci. 2009;336:592-598.

\section{Dovepress}

Journal Citation Reports/Science Edition, EMBase, Scopus and the Elsevier Bibliographic databases. The manuscript management system is completely online and includes a very quick and fair peer-review system, which is all easy to use. Visit http://www.dovepress.com/ testimonials.php to read real quotes from published authors. 